\title{
Multiple Forms of Chondroitinase AC from Arthrobacter aurescens
}

\author{
Keiichiro Hryama and Shigetaka OKadA \\ Department of Biochemistry, Osaka Municipal Technical Research Institute, \\ Kita-ku, Osaka, Osaka 530 \\ Received March 7, 1977
}

\begin{abstract}
While the isolated soil bacterium, Arthrobacter aurescens, had been found to secrete a chondroitinase $\mathrm{AC}$ into the culture medium, it was recognized that the chondroitinase preparation obtained from the broth of the strain cultured in a jar fermentor contained at least three electrophoretically separable components of the enzyme. Each component (named chondroitinase I, II, and III, respectively) was separated from the others by use of isoelectric focusing and then the enzymic properties of each component were examined.

The value of isoelectric point of each component differed from one another (I, $5.5 ; \mathrm{II}$, 5.9; III, 6.4). However, no difference could be detected in $\mathrm{pH}$-stability ( $\mathrm{pH} 5.0$ to 7.5), optimum $\mathrm{pH}\left(\mathrm{pH} 6.0\right.$ ), thermal stability (below $45^{\circ} \mathrm{C}$ ), optimum temperature $\left(50^{\circ} \mathrm{C}\right.$ ), substrate specificity (chondroitin $\mathrm{A}$ and $\mathrm{C}$ lyase), mode of action (endo type, the degree of multiple attack was 3.0 to 3.1 ), and the dissociation constant of the enzyme-substrate complex (Km for chondroitin sulfate $C$ was $3.3 \sim 3.6 \times 10^{-4} \mathrm{M}$ ). Thus the electrophoretically separable components with the chondroitinase activity were thought to be the multiple forms of the enzyme, chondroitinase AC. There was also no appreciable difference in the molecular weight values of those chondroitinase components, however, considerable difference was detected in the carbohydrate content of those components.
\end{abstract}

A strain of Arthrobacter aurescens which had been isolated from soil was recognized to secrete a chondroitinase AC [chondroitin AC lyase, EC 4.2.2.5] into the growth medium. ${ }^{1)}$ The strain was cultured in a shaking flask and then the produced chondroitinase was purified and crystallized by a simple procedure including the chromatography on SE-Sephadex and Sephadex G-100. The electrophoretic pattern of the purified chondroitinase showed that the enzyme preparation is homogeneous.

However, we noticed that the chondroitinase preparation, which had been obtained from the broth cultured in a jar fermentor and purified by the same procedure as above, consists of three electrophoretically separable components.

Yamagata et al. ${ }^{2}$ and Michelacci and Dietrich $^{3,4)}$ have published that a soil bacterium, Flavobacterium heparinum, produces several kinds of chondroitinases which can degrade chondroitin sulfate $\mathrm{C}$; chondroitinase $\mathrm{ABC}$ [EC 4.2.2.4], chondroitinase $\mathrm{AC}$, and chondroitinase C. They also presented that the culture conditions of the strain decide the production and the proportion of those enzymes. $^{3,4)}$ It is interesting to show whether Arthrobacter aurescens produces chondroitin sulfate-degrading enzymes other than chondroitinase $\mathrm{AC}$ or not. Accordingly, we examined to isolate the three components and to compare the enzymic properties of each component with others.

This paper describes the separation of three components in the chondroitinase preparation and those properties.

\section{MATERIALS AND METHODS}

Enzyme, Arthrobacter aurescens, strain IAM 110 65 (strain number of the Institute of Applied Microbiology, University of Tokyo), was grown in a medium containing $0.4 \%$ polypeptone, $0.4 \%$ bonito extract, and $0.2 \%$ chondroitin sulfate $\mathrm{C}$ at the initial pH 6.2 . After shaking for 2 days at $30^{\circ} \mathrm{C}$ in a $500-\mathrm{ml}$ shaking flask, $750 \mathrm{ml}$ of the cultured broth was inoculated into 15 liters of a new medium containing the same nutrients as above and grown at $30^{\circ} \mathrm{C}$ with aeration (about 5 
liters per min) and aggitation $180 \mathrm{rpm}$ in a 30 -liter jar fermentor. The cells grown for $8 \mathrm{hr}$ cultivation were removed by continuous centrifugation at $15,000 \times$ $g$. The supernatant fluid thus obtained was subjected to purification by use of the same procedure as described in our previous paper. ${ }^{1)}$ The purified chondroitinase, $28.1 \mathrm{mg}$, was obtained and crystallized by concentration using a collodion bag.

Chemicals. Chondroitin sulfate A (ratio of 4sulfate to 6 -sulfate, $4: 1$ ), dermatan sulfate, chondroitin sulfate $C$ (ratio of 6 -sulfate to 4 -sulfate, $9 ; 1$ ), hyaluronic acid, and authentic $\Delta 4,5$-unsaturated disaccharides ( $\Delta \mathrm{Di}-0 \mathrm{~S}, \Delta \mathrm{Di}-4 \mathrm{~S}$, and $\Delta \mathrm{Di}-6 \mathrm{~S}$ ) were purchased from Seikagaku Kogyo Co.

All other chemicals used were of analytical reagent grade.

Paper Chromatography. Paper chromatography was carried out using Toyo No. $50(40 \times 40 \mathrm{~cm})$ paper developed twice by the ascending technique in $l$-butanol : acetic acid: $1 \mathrm{~N}$ aq. ammonia $(2: 3: 1$ by volume). Each spot of unsaturated sugars and reducing sugars on the paper chromatogram was detected through exposure to ultraviolet light at $254 \mathrm{~nm}$ and by the silver nitrate method. ${ }^{5)}$

Analytical methods. Isoelectric focusing in $\mathrm{pH}$ gradients was performed by the method of Vesterberg and Svensson. ${ }^{6)} \quad$ Total sugar of mucopolysaccharides was assayed by the phenol-sulfuric acid method of Dubois et al. ${ }^{7)}$ Specific viscosity was measured at $40^{\circ} \mathrm{C}$ using an Ostwald viscosimeter. Polyacrylamide gel electrophoresis was performed at $3 \mathrm{~mA}$ per column for $2 \mathrm{hr}$ in a column $(0.48 \times 8 \mathrm{~cm})$ with $6.1 \%$ polyacrylamide gel containing $0.384 \mathrm{M}$ glycine-Tris buffer ( $\mathrm{pH} \mathrm{8.3).}{ }^{8)}$ SDS-polyacrylamide gel electrophoresis was performed in the same column as above with $5.0 \%$ polyacrylamide gel at a constant current of $5 \mathrm{~mA}$ per gel for $2 \mathrm{hr}$ according to the method of Weber and Osborn.? U1tracentrifugal analysis was performed through sedimentation velocity experiments in a Hitachi analytical centrifuge type UCA-1 at $20^{\circ} \mathrm{C}$ and a rotor speed of $55,960 \mathrm{rpm}$. Amino acid analysis was performed by the same procedure as described in our previous paper ${ }^{10)}$ using a Hitachi KLA-3B automatic amino acid analyzer. The content of neutral sugar and uronic acid in the enzyme was estimated by the orcinol-sulfuric acid method of Winzler. ${ }^{11\}}$

Assay of chondroitinase. The condition for the assay is as follows: $2 \mathrm{ml}$ of $0.125 \%$ chondroitin sulfate C containing $0.05 \mathrm{M}$ acetate buffer ( $\mathrm{pH} 6.0$ ) and $0.5 \mathrm{ml}$ of enzyme solution were mixed in a graduated $25-\mathrm{ml}$ test tube and glass-stoppered. After incubation at $40^{\circ} \mathrm{C}$ for $10 \mathrm{~min}$, the increment of reducing power was measured by Somogyi-Nelson's method. ${ }^{12)}$
The enzyme unit is defined as equal to the reducing power of unsaturated disaccharides ( $\mu$ mole) liberated per min from chondroitin sulfate $\mathrm{C}$ at $40^{\circ} \mathrm{C}$ and at $\mathrm{pH}$ $6.0(0.05 \mathrm{M}$ acetate buffer). The specific activity is defined as units of enzyme per mg of protein. ${ }^{1)}$

\section{RESULTS}

\section{Fractionation of three components of chondroiti- nase}

The purified chondroitinase $(27 \mathrm{mg}, 1950$ units) was subjected to isoelectrofocusing. This experiment was carried out in a $110-\mathrm{ml}$ column containing Ampholine carrier ampholyte (LKB Productor AB, Sweden) pH 5 to 8 (1\% by volume) for $36 \mathrm{hr}$ at 500 to 700 volts, 1.8 to $11 \mathrm{~mA}, 4^{\circ} \mathrm{C}$. Chondroitinase activity and protein were electrofocused in three peaks, chondroitinase I, II, and III, as shown in Fig. 1. The values of the isoelectric point of the chondroitinase components were found to be 5.5 (I), 5.9 (II), and 6.4 (III). The isoelectric point of chondroitinase I was in agreement with that of the chondroitinase preparation (5.46) which had been obtained

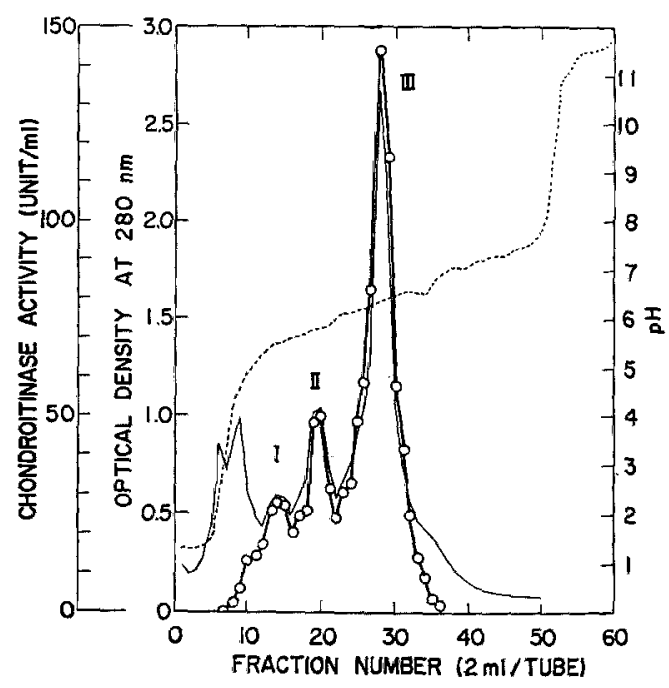

FIG. 1. Separation of Multiple Forms of Chondroitinase AC by the Method of Isoelectric Focusing of the Purified Chondroitinase Preparation.

$\mathrm{O}-\mathrm{O}$, chondroitinase activity; - - , protein content in optical density at $280 \mathrm{~nm}$ : ------, pH value of each fraction. Experimental conditions are described in the text. 


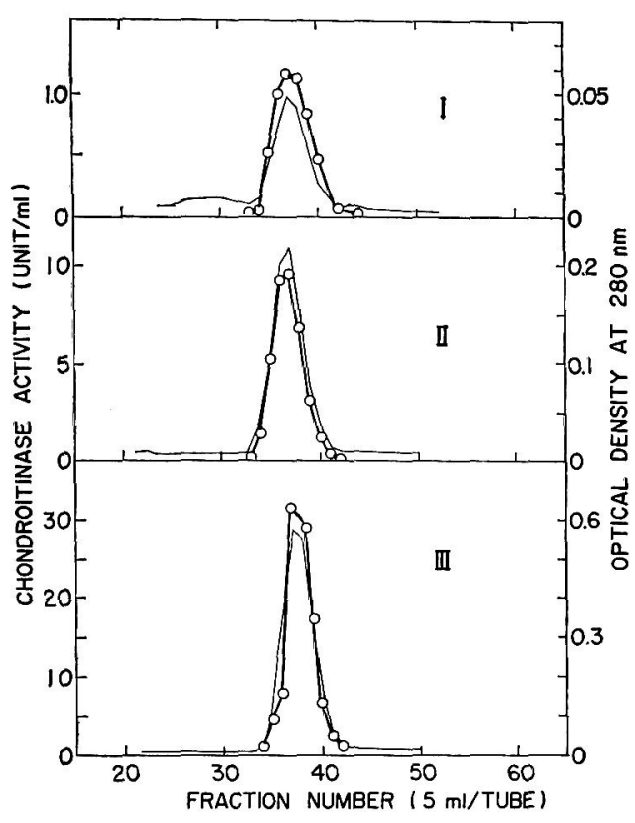

FIG. 2. Gel Filtration Chromatography of Fractionated Chondroitinase I, II, and III on a Sephadex G150 column.

$\mathrm{O}-\mathrm{O}$, chondroitinase activity; _- protein content in optical density at $280 \mathrm{~nm}$. Experimental conditions are described in the text. from the broth cultured in shaking flasks. The fractions No. 12 to 16 (I), No. 17 to 22 (II), and No. 23 to 36 (III) in Fig. 1 were collected and concentrated to $2 \mathrm{ml}$ using a collodion bag (Sartorius membrane filter, $\mathrm{GmbH}$, Germany) under reduced pressure, respectively. Each concentrated enzyme solution was subjected to gel filtration chromatography on a Sephadex G-150 column (2.0 $\times$ $130 \mathrm{~cm}$ ) equilibrated with $0.01 \mathrm{M}$ acetate buffer (pH 5.6). Figure 2 shows the gel filtration chromatograms. On each chromatogram the chondroitinase activity was eluted correspondingly with a single protein peak. The elution number of the peaks was nearly identical to each other. The chondroitinase fractions of each component were collected, dialyzed against distilled water, and concentrated to about $0.1 \mathrm{ml}$ using a collodion bag at $4^{\circ} \mathrm{C}$. Thus, the crystals of chondroitinase I, II, and III appeared as shown in Fig. 3.

Figure 4 shows the electrophoretic patterns of the chondroitinase preparations before and after separation. The electrophoresis was

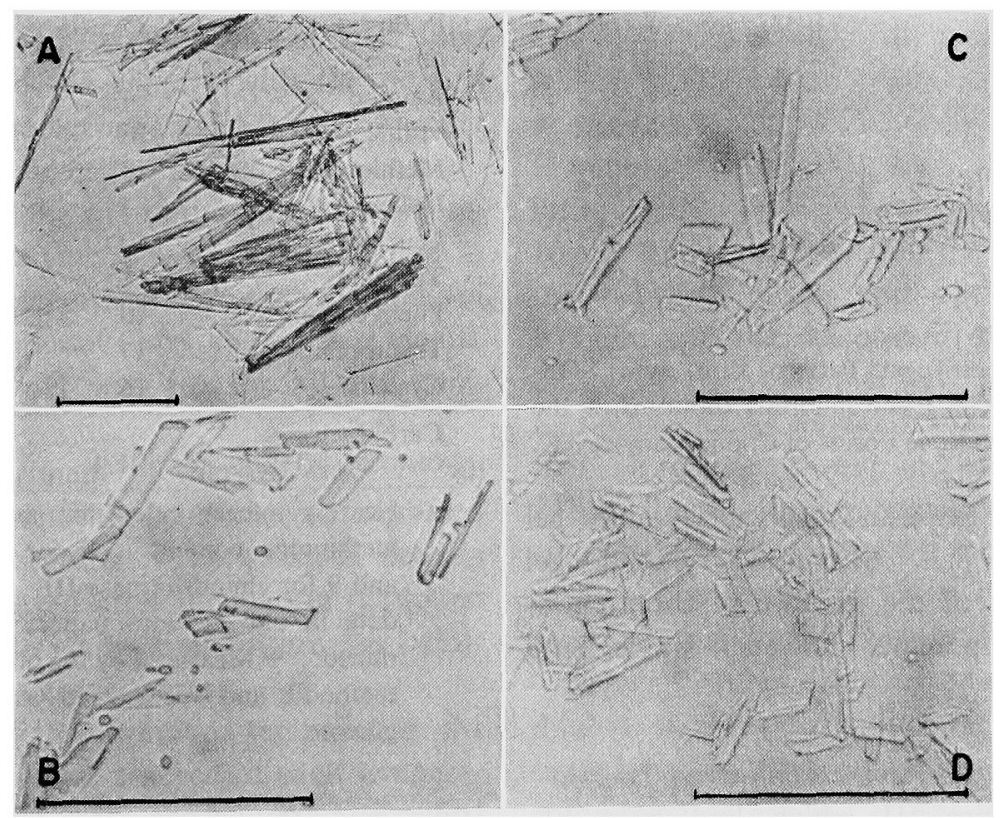

FIG. 3. Photographs of Crystalline Chondroitinase before (A) and after (B, C, and D) Separation of Multiple Forms.

A, before separation by electrophoresis; B, chondroitinase I; C, chondroitinase II; D, chondroitinase III. Lines drawn in the pictures indicate the length of $0.1 \mathrm{~mm}$. 


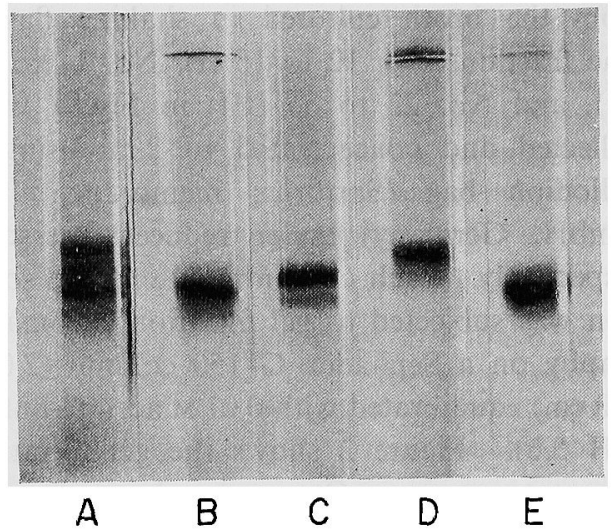

FIG. 4. Polyacrylamide Gel Electrophoresis of the Purified Chondroitinase Preparation before Separation of Multiple Forms (A), Chondroitinase I (B), Chondroitinase II (C), Chondroitinase III (D), and Pure Chondroitinase Obtained from the Broth Cultured in a Shaking Flask (E).

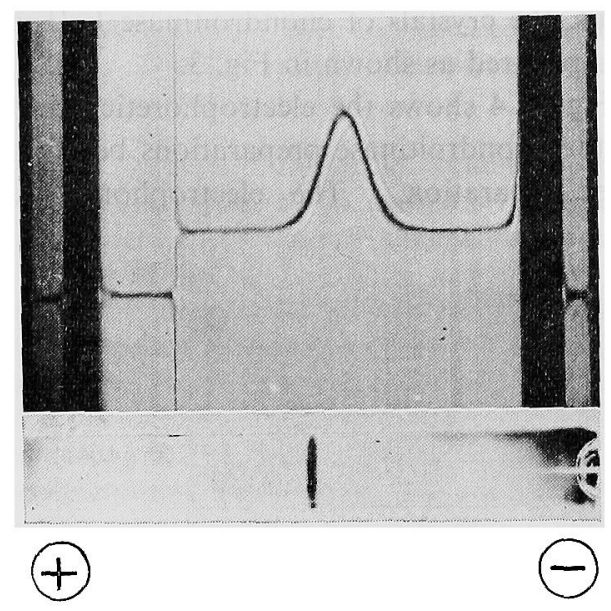

FIG. 5. Ultracentrifugal Pattern (top) and SDSPolyacrylamide Gel Electrophoresis (bottom) of the Mixture of the Multiple Forms of Chondroitinase AC.

performed in a usual polyacrylamide gel $(6.1 \%)$ at $\mathrm{pH}$ 8.3. SDS-polyacrylamide gel electrophoresis of the mixture of three chondroitinase components showed a single band (Fig. 5).

Amino acid analysis and carbohydrate content

Chondroitinase III which had been obtained in considerable quantity was supplied to the analysis of amino acid composition. Three portions of the enzyme $(2 \mathrm{mg})$ were hydrolyzed with $2 \mathrm{ml}$ of $6 \mathrm{M} \mathrm{HCl}$ for 24,48 , and $72 \mathrm{hr}$ at $110^{\circ} \mathrm{C}$ in evacuated, sealed tubes. Amino acids were analyzed by the method of Spackman et al. ${ }^{13)}$ According to the same procedure as described in our previous paper, the nearest integer was calculated on the assumption that the total amount of amino acids is nearly equal to that of chondroitinase I (methionine content is 9). Those values are listed in Table I with the data for chondroitinase I. $^{10)}$ The values of the carbohydrate content in chondroitinase I, II, and III are also listed in Table I.

TABle I. AMINo ACID COMPosition AND Carbohydrate Content of Chondroitinase I, II, AND III

\begin{tabular}{|c|c|c|c|}
\hline \multirow{2}{*}{ Amino acid $\left.{ }^{a}\right)$} & \multicolumn{3}{|c|}{ Chondroitinase } \\
\hline & $I^{b)}$ & II & III \\
\hline Lysine & 23 & & 21 \\
\hline Histidine & 12 & & 13 \\
\hline Arginine & 33 & & 37 \\
\hline Aspartic acid & 63 & & 67 \\
\hline Threonine & 59 & & 54 \\
\hline Serine & 46 & & 47 \\
\hline Glutamic acid & 45 & & 49 \\
\hline Proline & 23 & & 25 \\
\hline Glycine & 83 & & 78 \\
\hline Alanine & 94 & & 95 \\
\hline Valine & 56 & & 47 \\
\hline Methionine & 8 & & 9 \\
\hline Isoleucine & 23 & & 22 \\
\hline Leucine & 60 & & 59 \\
\hline Tyrosine & 18 & & 19 \\
\hline Phenylalanine & 20 & & 22 \\
\hline Tryptophan & 17 & & -c) \\
\hline Cysteine & 16 & & $\ldots c)$ \\
\hline
\end{tabular}

\section{Carbohydrate}

content $(\%)^{d)}$

4.1

2.7

3.1

a) Nearest integer calculated assuming that the methionine content is 8 for chondroitinase I and 9 for chondroitinase III, b) The published data in our previous paper.10) c) Not determined. ${ }^{d}$ ) Measured by the orcinol-sulfuric acid method $^{7)}$ and represented as the amount of glucose.

Effects of $p H$ and temperature on stability and activity

In the study of pH-stability, an aliquot of the enzyme solution was incubated at definite 

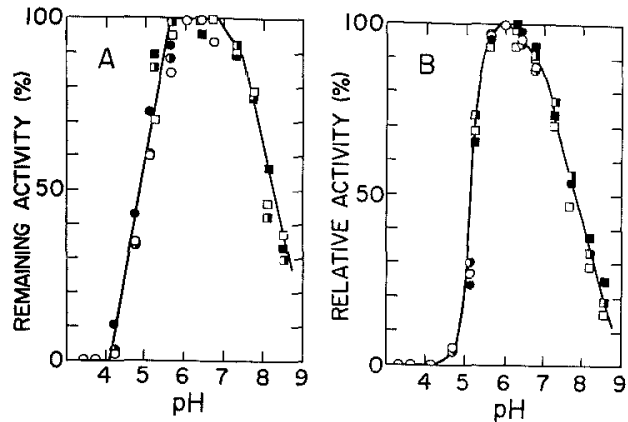

FIG. 6. Effect of $\mathrm{pH}$ on the Stability (A) and the Activity (B) of Chondroitinase I, II, and III.

In the experiments of $\mathrm{pH}$-stability, aliquots of the enzyme solution were incubated at the indicated $\mathrm{pH}$ in $0.01 \mathrm{M}$ acetate buffer (circle) or $0.01 \mathrm{M}$ phosphate buffer (square) at $40^{\circ} \mathrm{C}$ for $2 \mathrm{hr}$. After incubation an equal volume of $0.1 \mathrm{M}$ acetate buffer (pH 6.0) was added to each treated enzyme solution, and the residual activity was assayed. In the experiments of pH-activity, the enzyme activity was assayed at the indicated $\mathrm{pH}$ in $0.1 \%$ chondroitin sulfate $\mathrm{C}$ solution containing $0.04 \mathrm{M}$ acetate buffer (circle) or $0.008 \mathrm{M}$ phosphate buffer (square). Open, half-closed and closed symbols show chondroitinase I, II, and III, respectively.

$\mathrm{pH}$ and residual activity was assayed. All the three components, chondroitinase I, II, and III, maintained the activity with the portion of $80 \%$ or more between $\mathrm{pH} 5.0$ and 7.5 under the conditions described in Fig. 6A.

To compare the pH optimum of three components the enzyme activity was measured at definite $\mathrm{pH}$ according to the method of chondroitinase assay. As shown in Fig. 6B, the optimum $\mathrm{pH}$ was 6.0 for all the components.

In the experiment of thermal stability, an aliquot of the enzyme solution was incubated at each temperature. The residual activity which was assayed after incubation is plotted in Fig. 7A. The stable temperature was below $45^{\circ} \mathrm{C}$ for all the components.

To estimate the optimum temperature the enzyme activity was assayed at each temperature through the same procedure as described under MATERIALS AND METHODS. It was found that the optimum temperature was $50^{\circ} \mathrm{C}$ for all the components (Fig. 7B).
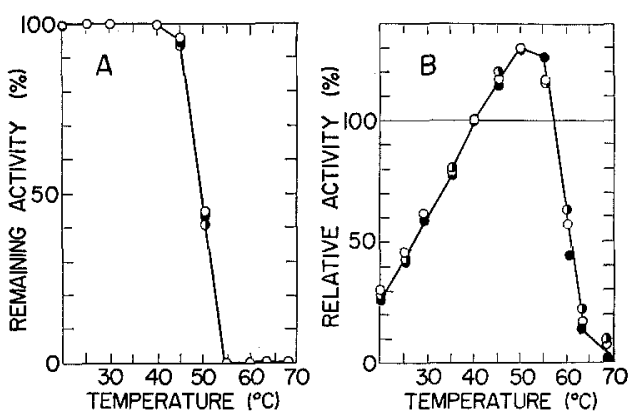

FIG. 7. Effect of Temperature on the Stability (A) and the Activity (B) of Chondroitinase I, II, and III.

In the experiments of temperature-stability, aliquots of the enzyme solution containing $0.02 \mathrm{M}$ acetate buffer ( $\mathrm{pH} \mathrm{6.0)}$ were incubated at each temperature for $15 \mathrm{~min}$. After incubation the enzyme solutions were cooled rapidly to $0^{\circ} \mathrm{C}$, maintained at the temperature for $30 \mathrm{~min}$, and the residual activity was assayed. In the experiments of temperature-activity, the enzyme activity was assayed at $20 \sim 68^{\circ} \mathrm{C}$ by the method described in Materials and Methods. Open, half-closed and closed circles show chondroitinase I, II, and III, respectively.

\section{Comparison of action of three chondroitinase components}

The solution of $1.25 \%$ chondroitin sulfate C (40 ml) was mixed with 0.125 enzyme unit per $\mathrm{ml}$ of each chondroitinase solution $(10 \mathrm{ml})$ and incubated at $40^{\circ} \mathrm{C}$. The reaction mixture $(5 \mathrm{ml})$ was withdrawn each time, immersed immediately into boiling water and heated for $10 \mathrm{~min}$ to stop the reaction. The increment of the reducing power and optical density at $232 \mathrm{~nm}$, and the decrease in the specific viscosity of each sample were measured with half-dilution. As shown in Fig. 8, it was found that the reducing power and optical density at $232 \mathrm{~nm}$ increase proportionally, and the specific viscosity decreases as the reaction proceeds. The profile of those curves for each component appeared likely with each other.

Figure 9 shows degradation curves of more diluted chondroitin sulfate $\mathrm{A}$ and $\mathrm{C}$ by the same concentration of each chondroitinase component as above. It was found that each component degrades those substrates to the extent of $100 \%$ (degradation ratio) to disaccharides. 

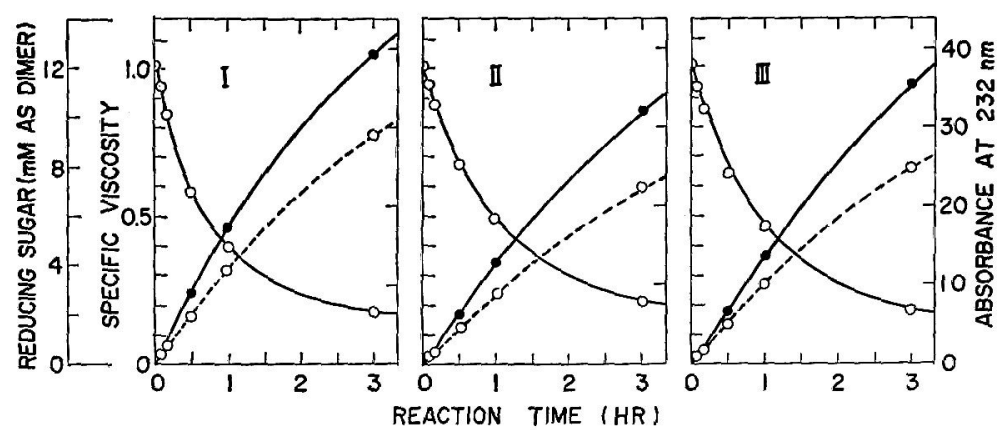

FIG. 8. Variation of Reducing Value, Ultraviolet Absorbance and Specific Viscosity of Chondroitin Sulfate C.

During the chondroitinase (I, II, and III) action. Incubation was carried out with $1.0 \%$ of chondroitin sulfate $C$ and 0.025 units per $\mathrm{ml}$ of each chondroitinase at $40^{\circ} \mathrm{C}$. These values were measured with half dilution. $\mathrm{O}--\mathrm{O}$, reducing value; $-\bullet$, optical density at $232 \mathrm{~nm} ; 0-0$, specific viscosity.

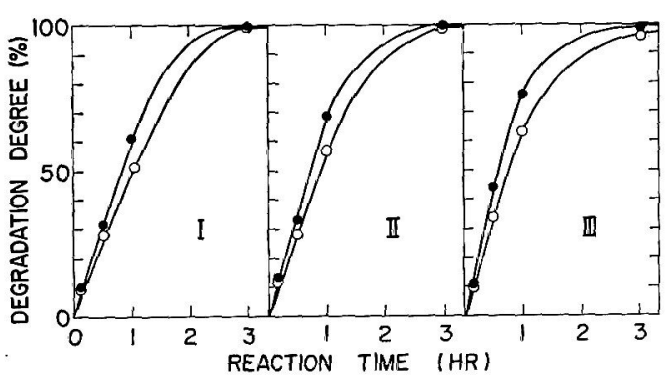

FIG. 9. Degradation Curves of Chondroitin Sulfate A $(O)$ and C ( $(\bullet)$ by Chondroitinase I, II, and III. The experiment was performed at $40^{\circ} \mathrm{C}$ with $0.1 \%$ substrate and $0.06 \sim 0.07$ units per $\mathrm{ml}$ of the enzyme solution at $\mathrm{pH}$ 6.0. The degradation degree is represented by the amount of liberated disaccharides.

Figure 10 shows a paper chromatogram of the reaction products obtained in the experiment shown in Fig. 9. The main spots of digests on the paper chromatogram showed absorption of ultraviolet light at $254 \mathrm{~nm}$ and corresponded to authentic unsaturated disaccharides ( $\Delta \mathrm{Di}-4 \mathrm{~S}$ and $\Delta \mathrm{Di}-6 \mathrm{~S}$ ). There was no significant difference in the digests of chondroitin sulfate $\mathrm{A}$ and $\mathrm{C}$ by chondroitinase I, II, and III.

The initial velocities of the action of chondroitinase I, II, and III on various mucopolysaccharides, including chondroitin sulfate A and $\mathrm{C}$, chondroitin, hyaluronic acid, and dermatan sulfate, were measured under the

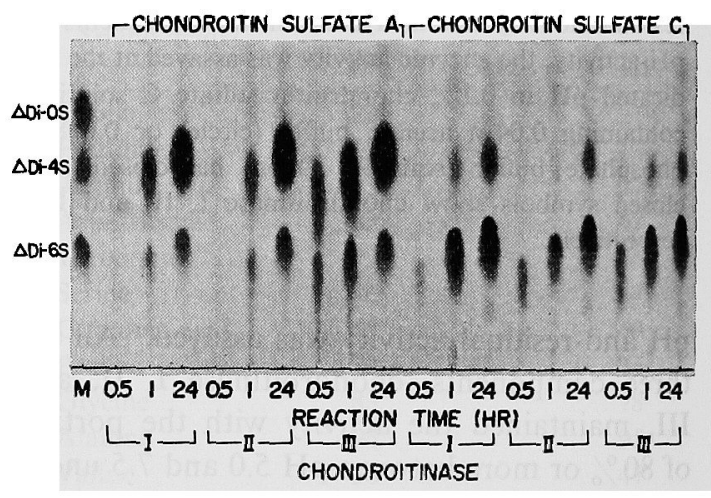

FIG. 10. Paper Chromatogram of the Digests from Chondroitin Sulfate $\mathrm{A}$ and $\mathrm{C}$ by Chondroitinase I, II, and III.

Samples at definite time were obtained in the experiment of Fig. 9. M indicates the mark, the authentic unsaturated disaccharides. Color development was carried out by the silver nitrate method ${ }^{5)}$ after developing twice by the ascending technique in the solvent system of 1-butanol-acetic acid-1 $\mathrm{N}$ aq. ammonia (2: 3: 1 by volume).

same condition of chondroitinase assay as mentioned previously. The initial rates are represented by a relative value to the rate for chondroitin sulfate A (Table II). It was found to be no difference in the substrate specificity of those electrophoretically separable components of the chondroitinase.

The Michaelis constants, $K m$, were estimated at $40^{\circ} \mathrm{C}$ for the action of those enzymes 
TABle II. COMParison OF THE ENZyMiC Properties of Chondroitinase I, II AND III

\begin{tabular}{|c|c|c|c|}
\hline \multirow{2}{*}{ Property } & \multicolumn{3}{|c|}{ Chondroitinase } \\
\hline & I & II & III \\
\hline Isoelectric point & 5.5 & 5.9 & 6.4 \\
\hline Molecular weight $\left.{ }^{a}\right)\left(\times 10^{4}\right)$ & 7.6 & 7.6 & 7.6 \\
\hline Specific activity ${ }^{b}$ & 74 & 72 & 81 \\
\hline Relative chondroitin sulfate $A$ & 1 & 1 & 1 \\
\hline rate $^{0)}$ chondroitin sulfate $C$ & 1.1 & 1.1 & 1.1 \\
\hline chondroitin & 1.9 & 1.9 & 1.9 \\
\hline hyaluronic acid & 3.2 & 3.2 & 3.2 \\
\hline dermatan sulfate & 0 & 0 & 0 \\
\hline $\begin{array}{l}K m \text { for chondroitin sulfate } \mathrm{C} \\
\left(40^{\circ} \mathrm{C}\right)\left(\times 10^{-4} \mathrm{M}\right)\end{array}$ & 3.6 & 3.3 & 3.5 \\
\hline Degree of multiple attack $d)$ & 3.1 & 3,1 & 3.0 \\
\hline
\end{tabular}

a) Estimated from the data of gel filtration, sedimentation velocity and SDS-polyacrylamide gel electrophoresis.

b) Calculated from the value of optical density at $280 \mathrm{~nm}$ assuming that one optical unit of the enzyme solution corresponds to $0.78 \mathrm{mg}$ per $\mathrm{ml}$ of chondroitinase. ${ }^{1)}$

c) Measured at $\mathrm{pH} 6.0,40^{\circ} \mathrm{C}$ and represented by relative values to the rate with chondroitin sulfate A.

d) Calculated by the method described in our previous paper. ${ }^{15}$ )

on chondroitin sulfate $\mathrm{C}$ in the same manner as described previously. ${ }^{14)}$ The degree of multiple attack on the action of those enzymes was estimated according to the method described in our previous paper. $^{15)}$ Those values are also listed in Table II. From the results it appeared that there is no significant difference among three chondroitinase components.

\section{DISCUSSION}

There have been several reports on a strain to produce some mucopolysaccharidases. Michelacci and Dietrich ${ }^{3,4}$ showed that Flavobacterium heparinum produces two kinds of constitutive chondroitinases which can degrade chondroitin sulfate $\mathrm{C}$ and an adaptive chondroitinase $B$. One of the constitutive chondroitinases can also degrade chondroitin sulfate $A$ but the other cannot degrade it. That is to say, they are not isozymes or multiple forms of chondroitinase AC. In contrast
Rautela and Abramson ${ }^{16 !}$ found that the enzyme preparation of Staphylococcus aureus contains multiple forms of hyaluronate lyase [EC 4.2.2.1] which are separable with the ion exchange chromatography on a column of CM-Sephadex.

In this publication, the purified chondroitinase AC preparation, which had been obtained from the broth of Arthrobacter aurescens cultured in a jar fermentor and purified by the same procedure as previous one, ${ }^{1 \prime}$ was found to separate into three fractions at the time when the preparation was supplied to electrophoresis. Among the fractions which had been named chondroitinase I, II and III, there was no significant difference in the enzymic properties including stability and optimal conditions with respect to $\mathrm{pH}$ and temperature, substrate specificity, mode of action, and the kinetic property. Thus the chondroitinase I, II and III seem to be multiple forms of Arthrobacter chondroitinase AC.

The multiple forms of a number of enzymes have been described by many investigator with respect to both mammalian and microbial enzymes. ${ }^{17)}$ For the generation of the multiple forms there are several possible causes: proteolysis resulting in formation of enzymatically active fragments, variation of the carbohydrate content, variation of the sulf hydryl-disulfide content, and attachment of nonenzymatic substances to the parts unrelated to enzymatic activity etc.

Although the values of isoelectric point of three chondroitinase fractions (I, II and III) were different with each other, i.e. 5.5 (I), 5.9 (II) and 6.4 (III), the molecular weights of the fractions were almost identical with each other as can be seen from Fig. 2 and Fig. 5. The fact was also suggested from the ultracentrifugal pattern of the mixture of three fractions, where the Schlieren profile had a good symmetry. Since the electrophoretic patterns of the separated fractions showed a nearly single band with a negligible band due to the slight contamination, each chondroitinase fraction seems not to change to the other in the procedure of electrophoresis. The amino 
acid composition of chondroitinase III was in agreement with that of chondroitinase I within $10 \%$ deviation. On the other hand, there were considerable deviations in the carbohydrate content of those chondroitinase fractions (I, II, and III). From these results alone, it is still not clear about the reason why the multiple forms occur to the chondroitinase AC.

Since chondroitinases are utilized as valuable analytical reagents for determination of the structure and the quantity of mucopolysaccharides, ${ }^{18,19)}$ the chondroitinase preparation is required to be homogeneous with respect to the substrate specificity. In view of the application, there may be no trouble in the use of the preparation of Arthrobacter chondroitinase $\mathrm{AC}$ obtained from the broth cultured in a jar fermentor even though the preparation contains the multiple forms of the chondroitinase $\mathrm{AC}$.

\section{REFERENCES}

1) K. Hiyama and S. Okada, J. Biol. Chem., 250, 1824 (1975).

2) T. Yamagata, H. Saito, O. Habuchi and S. Suzuki, ibid., 243, 1523. (1968).

3) Y. M. Michelacci and C. P. Dietrich, Biochem. J.,
151, 121 (1975).

4) Y. M. Michelacci and C. P. Dietrich, J. Biol. Chem., 254, 1154 (1976).

5) W. E. Trevelyan, D. P. Proctor and J. S. Harrison, Nature, 166, 444 (1950).

6) O. Vesterberg and H. Svensson, Acta Chem . Scand., 20, 820 (1966).

7) M. Dubois, K. A. Gilles, J. K. Hamilton, P. A. Reber and F. Smith, Anal. Chem., 28, 350 (1956).

8) B. J. Davis, Ann. N. Y. Acad, Sci., 121, 404 (1964).

9) K. Weber and M. Osborn, J. Biol. Chem., 244, 4406 (1969).

10) K. Hiyama and S. Okada, J. Biochem., 78, 1183 (1975)

11) R. J. Winzler, Methods Biochem. Anal., 2, 279 (1955).

12) N. Nelson, J. Biol. Chem., 153, 375 (1944).

13) D. H. Spackman, W. H. Stein and S. Moore, Anal. Chem., 30, 1190 (1958).

14) K. Hiyama and S. Okada, J. Biochem., 82, 429 (1977).

15) K. Hiyama and S. Okada, ibid., 80, 1209 (1976).

16) G.S. Rautela and C. Abramson, Arch. Biochem. Biophys., 158, 687 (1973).

17) C. Markert, "Isozymes," Academic Press Inc., New York, 1975.

18) H. Saito, T. Yamagata and S. Suzuki, J. Biol. Chem., 243, 1536 (1968).

19) S. Suzuki. H. Saito, T. Yamagata, K. Anno, N. Seno, Y. Kawai and T. Furuhashi, ibid., 243, 1543 (1968). 